\title{
Investigation of the electrochemical behaviour of lead dioxide in aqueous sulfuric acid solutions by using the in situ EQCM technique
}

\author{
Balázs Broda ${ }^{1} \cdot$ György Inzelt ${ }^{1}$ (D)
}

Received: 21 October 2019 / Revised: 21 October 2019 / Accepted: 15 November 2019 / Published online: 23 November 2019

(C) The Author(s) 2019

\begin{abstract}
The charge-discharge characteristics and the aging mechanism of $\mathrm{PbO}_{2}$ layers in contact with sulfuric acid solutions of different concentrations (1.5-5.0 M) were studied by using combined cyclic voltammetry and electrochemical quartz crystal microbalance (EQCM) techniques. For this purpose, thick lead dioxide layers were electrodeposited on gold substrate from aqueous solutions of $\mathrm{Pb}\left(\mathrm{NO}_{3}\right)_{2}$ dissolved in nitric acid. Based on the electrochemical and the mass change responses, it was found that in more concentrated solutions of $\mathrm{H}_{2} \mathrm{SO}_{4}$, the main reduction reaction was the transformation of lead dioxide to lead sulfate. However, in less concentrated sulfuric acid media, the transformation of lead dioxide to lead(II) ion became the main reaction. These $\mathrm{Pb}^{2+}$ ions transformed into lead sulfate crystals later by a chemical reaction. Because the electrochemical oxidation of lead sulfate is less favourable in sulfuric acid medium of higher concentrations, thus, $\mathrm{PbO}_{2}$ layers cannot be tested by continuous cyclization, which is necessary to study their aging parameters. Therefore, a delay step before each cyclic voltammogram was applied while the nonconductive lead sulfate dissolves or alternatively, by applying a pre-oxidation step prior to each cyclic voltammetry experiment to produce electrochemically significant amount of lead dioxide which can be reduced during the following negative potential sweep.
\end{abstract}

Keywords Lead dioxide $\cdot$ EQCM $\cdot$ Cyclic voltammetry $\cdot$ Lead-acid battery

\section{Introduction}

Lead dioxide layers and porous materials are widely used in industrial applications, e.g. common [1] and novel [2] (bipolar [3] and semi-bipolar [4]) lead-acid batteries, waste water treatment [5], and many other purposes [6-8]. Several studies concerning the electrochemical characterization of $\mathrm{PbO}_{2}$ films (charge-discharge characteristics, aging processes) have been carried out previously [9-12]. However, in the majority of these investigations, only electrochemical methods have been used. It is evident that other complementary techniques are

Balázs Broda

balazsbroda@gmail.com

György Inzelt

inzeltgy@ caesar.elte.hu

1 Department of Physical Chemistry, Eötvös University, P.O. Box 32, Budapest 112 H-1518, Hungary needed to get a deeper insight into the charging-discharging and aging behaviour of these materials.

The mass changes during the immersion of electrodeposited pure $\beta-\mathrm{PbO}_{2}$ layers in different concentrations of sulfuric acid solutions and their electrochemical behaviour in $1.5 \mathrm{M}$ $\mathrm{H}_{2} \mathrm{SO}_{4}$ electrolyte using cyclic voltammetry experiments were investigated by Pech et al. [13]. It was concluded that a hydrated layer was formed on the surface of lead dioxide crystallites whose composition and thickness were independent from the concentration of the sulfuric acid solution. The degree of hydration was also determined based on the following reaction:

$\mathrm{PbO}_{2}($ crystal $)+x \mathrm{H}_{2} \mathrm{O} \rightleftharpoons \mathrm{PbO}(\mathrm{OH})_{2} \cdot(x-1) \mathrm{H}_{2} \mathrm{O}($ gel $)$

where $x$ was equal to 8.1 in that system. It was shown that both the crystalline and gelled $\mathrm{PbO}_{2}$ were transformed to lead sulfate during discharge. The gel zone that was consumed during the first cycle was regenerated from the remaining lead dioxide crystals reacting with the electrolyte according to Reaction 1. This 
rehydration process was complete at low scan rates but only partially complete at higher ones.

Combined electrochemical and gravimetric studies of lead dioxide layers with different $\alpha / \beta \mathrm{PbO}_{2}$ ratios have been carried out by Wei et al. [14]. The $\mathrm{PbO}_{2}$ films were immersed into 4.4 $\mathrm{M} \mathrm{H}_{2} \mathrm{SO}_{4}$ solution; thus, gel zones were formed on their surfaces. The amount of hydrated lead dioxide was different in each case depending on the $\alpha / \beta$ ratio of $\mathrm{PbO}_{2}$. The largest and the smallest values were measured in the case of samples with the ratio of 0.3 and 1.0, respectively. However, the cycle stabilities of the films with the $\alpha / \beta$ ratio of 1.0 and pure $\beta-\mathrm{PbO}_{2}$ were the best and the worst, respectively.

The electrochemical quartz crystal microbalance (EQCM) is a powerful technique for monitoring in situ mass changes on the electrode surface during different physicochemical processes (transformation of species with different molar masses, adsorption-desorption, electrodeposition, the rates of these events, etc.). Useful information can be provided by EQCM to understand the mechanism of electrochemical reactions in more details. Based on the Sauerbrey equation [15] and Faraday's law of electrolysis, effective molar mass changes related to the participating species can be calculated. Although, the EQCM is a very common method for the investigation of metal- and metaloxide layers, it has rarely been used for studying the chargingdischarging characteristics of $\mathrm{PbO}_{2}[16]$.

The main goal of this paper is to characterize the electrodeposited $\mathrm{PbO}_{2}$ layer on gold substrate in sulfuric acid solutions of different concentrations and to investigate the aging mechanism during charge-discharge cycles.

\section{Experimental}

A conventional three-electrode electrochemical cell was used for the experiments containing a gold-coated quartz crystal as the working electrode $(5 \mathrm{MHz}$ AT-cut, the geometric area during electrodeposition was $1.37 \mathrm{~cm}^{2}$ ) and a gold plate as the counter electrode. A spatially separated sodium chloride-saturated calomel electrode (SCE) was used as the reference electrode. Lead(II) solutions were prepared by dissolving $\mathrm{Pb}\left(\mathrm{NO}_{3}\right)_{2}$ (Reanal, 99\%) in ultrapure water (Millipore) and nitric acid (Merck). The electrolytes, $\mathrm{Pb}$ (II) solution for the electrodeposition and sulfuric acid (Merck) for the investigation, were deaerated to remove the dissolved oxygen by bubbling high-purity argon for $15 \mathrm{~min}$. All experiments were carried out at $25{ }^{\circ} \mathrm{C}$ without using stirring to avoid the effects of vibration of the solution and external noise.

The relationship between the measured frequency change $(\Delta f)$ and the mass change per unit area $(\Delta m)$ is given by the Sauerbrey equation [15]:

$\Delta f=-C_{\mathrm{f}} . \Delta m$ where $C_{\mathrm{f}}$ is the integral sensitivity factor for the crystal used which is $56.6 \mathrm{~Hz} \mathrm{mg}^{-1} \mathrm{~cm}^{2}$ for a 5-MHz AT-cut quartz crystal at $25^{\circ} \mathrm{C}$. The resonant frequency is influenced by the viscosity and the density of the solution [17]. The frequencies of the quartz crystals (Stanford Research System) mounted in the holder made from Kynar and connected to an SRS QCM 100 unit were measured by a Philips PM 6685 frequency counter. The electrochemical measurements were performed with an Electroflex EF453 potentiostat.

\section{Results and discussion}

\section{Electrodeposition and reduction of $\mathrm{PbO}_{2}$ layers in nitrate media}

EQCM experiments (Fig. 1a) were carried out on gold-coated quartz crystal in $0.1 \mathrm{M} \mathrm{Pb}\left(\mathrm{NO}_{3}\right)_{2}$ dissolved in $1.0 \mathrm{M} \mathrm{HNO}_{3}$ solution to study of the behaviour of the gold substrate and the electrodeposition process [18]. The effective molar mass of the electrodeposited species was calculated to ca. $242 \mathrm{~g} / \mathrm{mol}$ according to Eq. 2 and Faraday's law of electrolysis which corresponds to the transformation of $\mathrm{Pb}^{2+}$ ion into $\mathrm{PbO}_{2}$ $(239.2 \mathrm{~g} / \mathrm{mol})$ with a very small extent of hydration. After that, practically pure $\beta-\mathrm{PbO}_{2}$ layer was electrodeposited by chronoamperometric method in the same medium (Fig. 1b and Table 1).

The result of the effective molar mass calculation shows that between 240 and $320 \mathrm{~s}$ of chronoamperometric experiment, the change is equal to ca. $240 \mathrm{~g} / \mathrm{mol}$ which is in good agreement with the electrodeposition of crystalline $\mathrm{PbO}_{2}$. Before this prepared layer was immersed into sulfuric acid solution, it was washed firstly with ultrapure water, then with $\mathrm{H}_{2} \mathrm{SO}_{4}$ electrolyte.

The thickness of the $\mathrm{PbO}_{2}$ layer can be estimated on the basis of the calculated mass change during the electrodeposition $(235 \mu \mathrm{g})$ divided by the density of porous lead dioxide and the geometric surface area of the electrode $\left(1.37 \mathrm{~cm}^{2}\right)$. However, the density of the crystalline $\mathrm{PbO}_{2}$ is $9.38 \mathrm{~g} / \mathrm{cm}^{3}$; the prepared material is porous and contains water in a small but not negligible quantity. Based on literature data [1], the density of such type of films is between ca. $3.75 \mathrm{~g} / \mathrm{cm}^{3}$ and ca. $5.0 \mathrm{~g} / \mathrm{cm}^{3}$. The estimated thickness is between 0.34 and $0.46 \mu \mathrm{m}$.

\section{Electrochemical investigation of electrodeposited $\mathrm{PbO}_{2}$ layers in sulfuric acid solutions}

\section{General effects of sulfuric acid concentration on $\mathrm{PbO}_{2}$ electrochemistry}

The concentration of the electrolyte can significantly influence the electrochemical behaviour of the electrodeposited 


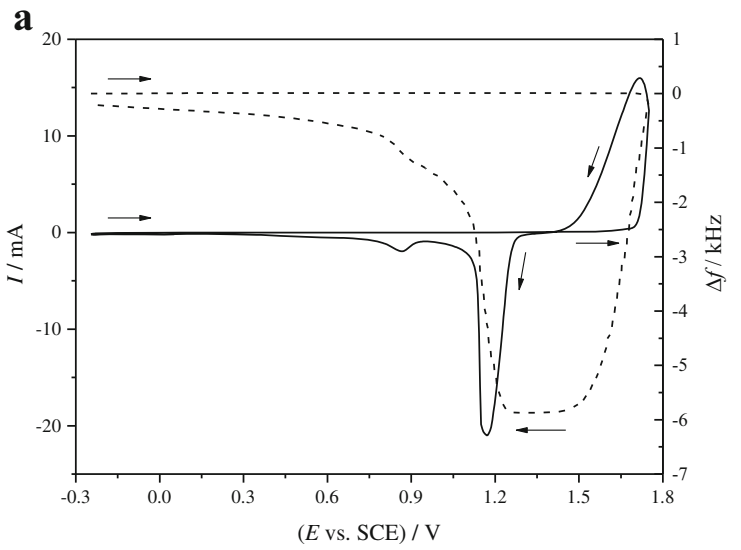

Fig. 1 a Cyclic voltammogram (solid line) and simultaneous frequency measurement (dashed line) during the electrodeposition of $\mathrm{PbO}_{2}$ on a gold-coated quartz crystal from the solution containing $0.1 \mathrm{M} \mathrm{Pb}\left(\mathrm{NO}_{3}\right)_{2}$ and $1.0 \mathrm{M} \mathrm{HNO}_{3}$ at a scan rate of $20 \mathrm{mV} \mathrm{s}^{-1}$. b Chronoamperometric

lead dioxide layers since ions of the electrolyte and the solvent molecules participate in the electrode processes. Cyclic voltammograms were measured in media containing different amounts of sulfuric acid near the working concentration region of $\mathrm{H}_{2} \mathrm{SO}_{4}$ in a real lead-acid battery cell $(1.5-5.0 \mathrm{M})$ [1]. It was experienced that the layer underwent different changes during the cyclization depending on the concentration of the electrolyte: in dilute acids, the formation of lead dioxide was preferable, whereas in concentrated acids, the formation of lead sulfate was rather preferred. In order to study this phenomenon in more detail, $\mathrm{PbO}_{2}$ layers were cycled between +1.8 and $+0.4 \mathrm{~V}$ vs. SCE at a scan rate of $50 \mathrm{mV} \mathrm{s}^{-1}$ until constant cyclic voltammograms were achieved. These voltammograms and simultaneous frequency measurements are shown in Fig. 2 a and b, respectively.

The reduction peak potentials shift due to the concentration change of the sulfuric acid medium as the hydrogen ion and/or water and/or sulfate ion are involved in the reaction. The theoretically estimated activities of these species are listed in Table 2 .

During the cathodic scan, the peak appearing at more positive potential belongs to the reduction of lead dioxide (Reactions 3a and 3b) in sulfuric acid solution [21].

$\mathrm{PbO}_{2}+4 \mathrm{H}^{+}+\mathrm{SO}_{4}^{2-}+2 \mathrm{e}^{-} \rightleftharpoons \mathrm{PbSO}_{4}+2 \mathrm{H}_{2} \mathrm{O}$
$\mathrm{PbO}_{2}+3 \mathrm{H}^{+}+\mathrm{HSO}_{4}^{-}+2 \mathrm{e}^{-} \rightleftharpoons \mathrm{PbSO}_{4}+2 \mathrm{H}_{2} \mathrm{O}$

The peak at less positive potential belongs to the reduction of gold(III) oxide (Reaction 4) in acidic medium [22].

$\mathrm{Au}_{2} \mathrm{O}_{3}+6 \mathrm{H}^{+}+6 \mathrm{e}^{-} \rightleftharpoons 2 \mathrm{Au}+3 \mathrm{H}_{2} \mathrm{O}$

Table 1 Potential steps applied during electrodeposition of the $\mathrm{PbO}_{2}$ layer

\begin{tabular}{lllllllll}
\hline$t / \mathrm{s}$ & 0 & 40 & 80 & 120 & 160 & 200 & 240 & 320 \\
\hline$(E$ vs. SCE $) / \mathrm{V}$ & 0.80 & 1.00 & 1.20 & 1.40 & 1.50 & 1.55 & 1.60 & OCP \\
\hline
\end{tabular}

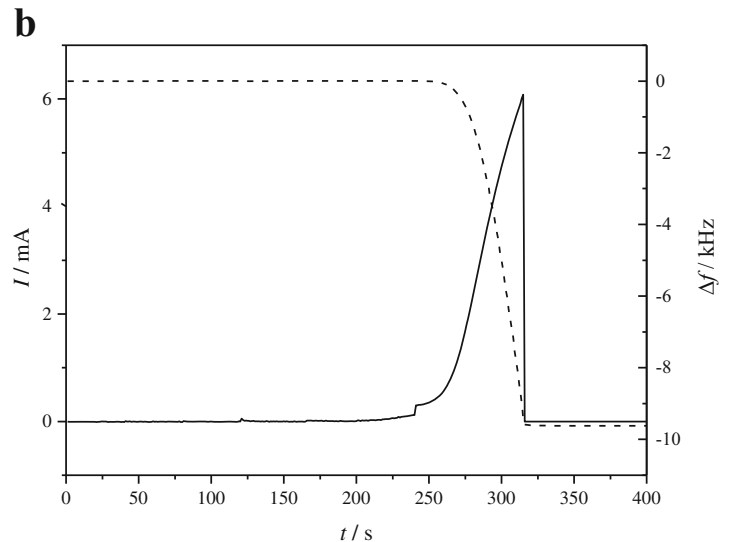

curve (solid lines) and simultaneous frequency measurements (dashed lines) during electrodeposition on gold-coated quartz crystal from the solution mentioned above. The potential vs. time function is shown in Table 1

Both Reactions $3 \mathrm{a}$ and $3 \mathrm{~b}$ can be written as a significant amount of hydrogen sulfate and sulfate ion exists in such a concentrated sulfuric acid medium as it is shown in Fig. 3.

The calculation of the potential shift of reduction peaks of lead dioxide due to the concentration change of the electrolyte can be carried out based on both Reactions $3 \mathrm{a}$ and $3 \mathrm{~b}$. In this case, Reaction 3a was used because sulfate ion activities are reported in ref. [20] instead of hydrogen sulfate activity values. The calculated and the measured potential shifts are listed in Table 3.

The potential shifts of $\mathrm{PbO}_{2} / \mathrm{PbSO}_{4}$ system show a good relationship with the calculated values according to Reaction $3 \mathrm{a}$ at lower $\mathrm{H}_{2} \mathrm{SO}_{4}$ concentrations, although they have a high error at high concentrations. The $\mathrm{Au}_{2} \mathrm{O}_{3} / \mathrm{Au}$ systems show significantly smaller $\mathrm{pH}$ dependence than it is expected according to Reaction 4 mainly in the cases of smaller concentrations. In more concentrated media, a significant process is the depletion of sulfuric acid inside the pores according to Reaction 3. That is why, the real concentration inside the layer (even in the vicinity of the gold surface) could be lower than that in the bulk solution resulting in potential shifts of the reduction peaks.

Based on the mass changes, it is stated that in all cases, the $\mathrm{PbO}_{2}$ reduction started according to Reaction $3 b$ but after a while, the frequency increased significantly which means that the transformation of lead dioxide to lead(II) ion became the main reaction. These $\mathrm{Pb}^{2+}$ ions transformed into lead sulfate crystals later by chemical reaction or by electrochemical reaction at high positive potentials during the reverse sweep. In the case when less concentrated acid was the medium, the chemical reaction was the dominant because of the lower concentration of sulfate species; however, the electrochemical reaction was the main process as $\mathrm{PbSO}_{4}$ was formed in more concentrated media. The mean value of the effective molar masses calculated for the reduction peak of gold(III) oxide was ca. $10 \mathrm{~g} / \mathrm{mol}$ (regarding to $1 \mathrm{~mol} \mathrm{e}^{-}$) which was in very 
a

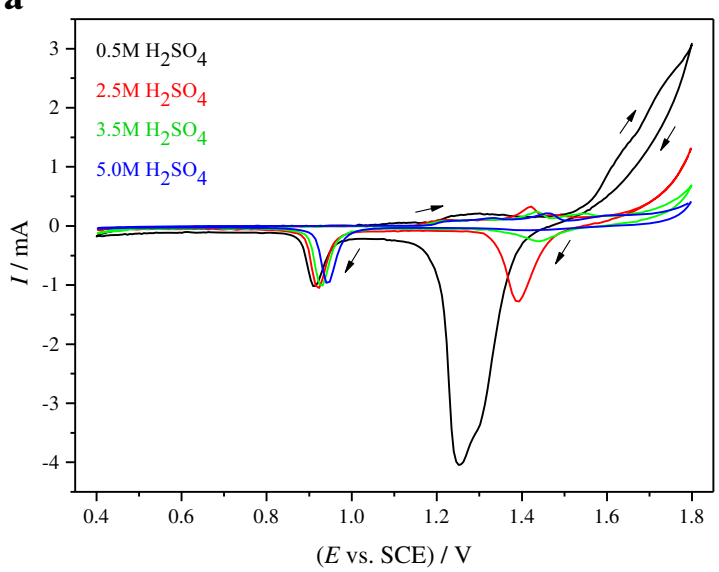

b

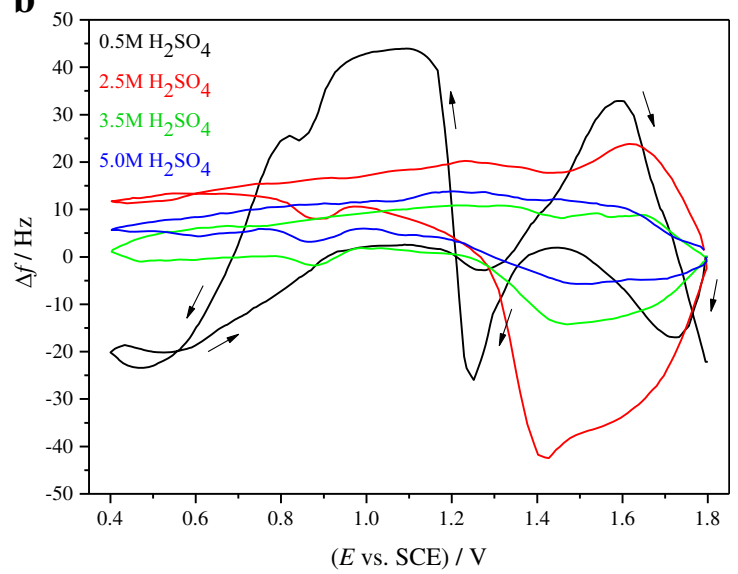

Fig. 2 a Cyclic voltammograms obtained for lead dioxide layers in $\mathrm{H}_{2} \mathrm{SO}_{4}$ solutions of different concentrations (black $0.5 \mathrm{M}$, red $2.5 \mathrm{M}$, green $3.5 \mathrm{M}$, blue $5.0 \mathrm{M}$ ) at a scan rate of $50 \mathrm{mV} \mathrm{s}^{-1}$ in the potential range of +1.8 to $+0.4 \mathrm{~V}$ vs. SCE. b Simultaneous frequency measurements

good agreement with $9 \mathrm{~g} / \mathrm{mol}$ (theoretical value according to Reaction 4).

\section{Relaxation of lead dioxide layers at open-circuit potential}

To study the time dependency of the charging-discharging characteristics of the prepared layer, cyclic voltammograms were taken in $5 \mathrm{M}$ sulfuric acid solution (Fig. 4).

The reduction of $\mathrm{PbO}_{2}$ in more concentrated sulfuric acid is preferred to its formation via the oxidation of $\mathrm{PbSO}_{4}$. From cycle to cycle, only ca. $15 \%$ of the formed lead sulfate can be reoxidized. However, the amount of lead dioxide reduced in the first cycle (ca. $30 \mu \mathrm{g}$ ) is only the $13 \%$ of the whole electrodeposited amount. It means that a practically nonconductive and less dense lead sulfate layer covered the inner lead dioxide; thus, it became temporarily electrochemically inactive. It is shown in Fig. $4 \mathrm{~b}$ that if a 5-min waiting time was applied after the third cycle, larger amount of $\mathrm{PbO}_{2}$ could be reduced in the next cycle. Both the dissolution of the $\mathrm{PbSO}_{4}$ layer and the acid replacement (during reduction reaction according to Reactions $3 \mathrm{a}$ and $3 \mathrm{~b}$, the sulfuric acid is consumed; thus, more diluted acid remains in the pores) by diffusion can explain this phenomenon.

The calculated effective molar mass changes belonging to the peak appeared between +1.3 and $+1.4 \mathrm{~V}$ vs. SCE (reduction of lead dioxide) in the successive cycles were $65 \mathrm{~g} / \mathrm{mol}, 15 \mathrm{~g} / \mathrm{mol}, 6 \mathrm{~g} / \mathrm{mol}, 8 \mathrm{~g} / \mathrm{mol}$, and $7 \mathrm{~g} / \mathrm{mol}$ (regarding to $1 \mathrm{~mol} \mathrm{e}^{-}$), respectively. It means that practically pure crystalline $\mathrm{PbO}_{2}$ was transformed onto lead sulfate in the first cycle (theoretical value is $64 \mathrm{~g} / \mathrm{mol}$ according to Reactions $3 \mathrm{a}$ and $3 \mathrm{~b}$ ). However, in the beginning of the second cycle, lead dioxide contained water in a higher extent resulted in molar mass increase (because of additional water according to Reaction 1); thus, smaller molar mass changes were experienced. The extent of hydration of the layer increased monotonously from cycle to cycle, except between the $3 \mathrm{rd}$ and 4 th cycles when a 5-min waiting time was applied. During this period, the recrystallization of gelled material took place confirming the assumption made in ref. [23].

The effective molar mass calculated belonging to the reduction peak of gold(III) oxide in the successive cycles was ca. $9 \mathrm{~g} / \mathrm{mol}$ (regarding to $1 \mathrm{~mol} \mathrm{e}^{-}$) which was perfectly in line with the theoretical value according to Reaction 4. However, the potential of the reduction peak of gold(III) oxide changed during the cyclization depending on how concentrated acid was present in the vicinity of the Au surface. It is seen that it is a good correlation between the potential of this peak and the current for reducing lead dioxide. After the 5-min waiting time, not only the current of the reduction peak at more positive potential increased, but also the peak potential belonging

Table 2 Sulfuric acid molarity and molality values; logarithm of theoretically estimated activities of $\mathrm{H}^{+}$ion, $\mathrm{SO}_{4}^{2-}$ ion, and water; and the measured reduction peak potentials $[19,20]$

\begin{tabular}{llccccc}
\hline Molarity $\left(\mathrm{mol} \mathrm{dm}^{-3}\right)$ & Molality $\left(\mathrm{mol} \mathrm{kg}^{-1}\right)$ & $\log \left(\boldsymbol{a}_{\mathbf{H}^{+}}\right)$ & $\log \left(\boldsymbol{a}_{\mathbf{S O}}^{2-}\right)$ & $\log \left(\boldsymbol{a}_{\mathbf{H}_{2} \mathbf{O}}\right)$ & $E_{\mathrm{peak}, \mathrm{R} 1} / \mathrm{V}$ & $E_{\mathrm{peak}, \mathrm{R} 2} / \mathrm{V}$ \\
\hline 0.5 & 0.49 & -0.34 & -2.15 & -0.01 & 1.27 \\
2.5 & 2.78 & 0.65 & -2.04 & -0.06 & 1.39 \\
3.5 & 4.08 & 0.97 & -1.92 & -0.11 & 1.44 & 0.92 \\
5.0 & 6.29 & 1.45 & -1.73 & -0.22 & 1.44 & 0.93 \\
\hline
\end{tabular}




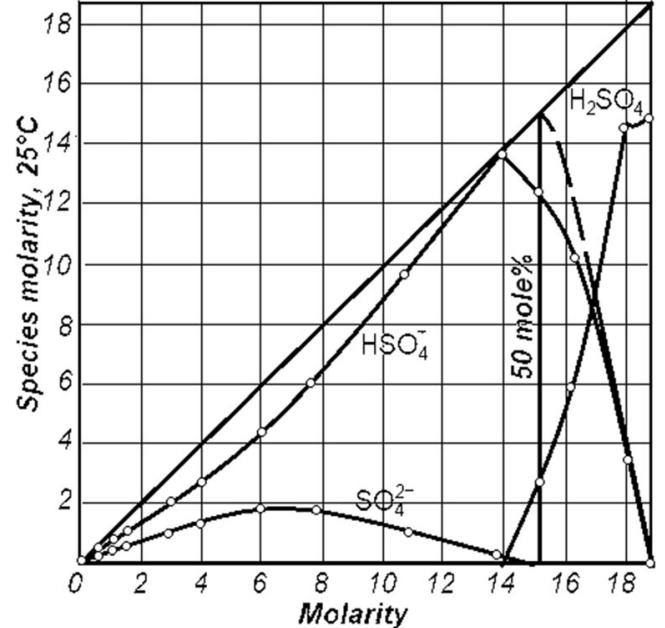

Fig. 3 Distribution of sulfate species in sulfuric acid solutions [19]

to $\mathrm{Au}_{2} \mathrm{O}_{3}$ reduction shifted to negative direction. It is concluded that the reason of these two processes is the same, the depletion of sulfuric acid inside the layer during the transformation of $\mathrm{PbO}_{2}$ to $\mathrm{PbSO}_{4}$. This phenomenon proved that the $\mathrm{Au}_{2} \mathrm{O}_{3} / \mathrm{Au}$ electrode could be suitable for using as an internal reference in this complex electrochemical system. To get a deeper insight into this process, the relaxation of the lead dioxide layer after different waiting times (after 10 cycles when constant cyclic voltammograms could be obtained) was studied in $5.0 \mathrm{M} \mathrm{H}_{2} \mathrm{SO}_{4}$ solution (Fig. 5).

The open-circuit potential of the lead dioxide/lead sulfate system (Reaction 3a) in this medium can be determined based on the Nernst equation; the calculated value is $+1.50 \mathrm{~V}$ vs. SCE [24]. However, during this determination, it is assumed that $\mathrm{PbO}_{2}$ exists in crystalline form, only, but the amount of gelled form is also significant. The existing of both crystalline and gelled material results in a mixture potential which is higher than the previously calculated value [23]. According to the experimental data, ca. $+1.55 \mathrm{~V}$ vs. SCE can be assumed.

In the course of subsequent cyclic voltammograms, the aging of the layer became increasingly significant; thus, the characteristics of the curves were dependent not only on the waiting times but also on the number of previously obtained CVs. These effects could be explained by the decrease of the porosity of the film because of the large difference between the molar volumes of lead dioxide (i.e. 100\%) and lead sulfate (i.e. 192\%). Sulfuric acid was consumed during the reduction and $\mathrm{PbSO}_{4}$ formed (Reaction 3a); thus, more dilute sulfuric acid was present in the smaller pores, which was indicated by the diffusion-like characteristics of the potential vs. time function. The potential difference between the initial one and the OCP also increased by the aging of the film, and less and less amount of $\mathrm{PbO}_{2}$ could be reduced during those 10 cycles (Fig. 6a, b). It proved that the amount of sulfuric acid stored in the pores significantly decreased during the consecutive charging-discharging cycles. Similar conclusion could be drawn from the behaviour of the frequency curves. The initial slopes decreased by time because a less amount of sulfuric acid must have been replaced in the pores by diffusion as less amount of it was consumed in the previous cycles. Besides that, each curve tried to achieve a certain but different frequency values; the differences between these values were caused by the mass increase of unreacted lead sulfate from cycle to cycle.

The total amount of reducible $\mathrm{PbO}_{2}$ decreased during cyclization until constant $\mathrm{CV}$ could be obtained. The first and the constant cyclic voltammograms with simultaneous frequency measurements in $5.0 \mathrm{M}$ sulfuric acid solution are shown in Fig. 6 a and b, respectively.

During the waiting after these 10 cycles, sulfuric acid could reach the surface of the electrochemically active lead dioxide. Thus, the reduction peak current belonging to the $\mathrm{PbO}_{2} /$ $\mathrm{PbSO}_{4}$ transformation increased during the next first cycle, then continuously decreased from cycle to cycle. The oxidation of lead sulfate started at lower positive potentials in less concentrated acids (Fig. 2a), attesting that the oxidized lead sulfate contacted with more dilute sulfuric acid in the pores. However, the reduction peak of $\mathrm{Au}_{2} \mathrm{O}_{3}$ is a much better choice for internal reference as it is $\mathrm{pH}$ dependent but practically independent from the chemical forms of lead compounds. If a larger amount of lead dioxide was reduced during the negative potential sweep, the reduction peak of gold(III) oxide shifted to a less positive potential which supported the idea that the $\mathrm{pH}$ in the vicinity of the gold surface decreased to a greater extent according to Reactions $3 a$ and $3 b$.

During cyclization, the sulfuric acid was depleted inside the layer; however, based on the effective molar mass changes, the ratio of crystalline/gelled $\mathrm{PbO}_{2}$ transformed to lead sulfate in each cycle decreased minimally, even the amount of $\mathrm{PbSO}_{4}$ which was no longer being oxidizable under these conditions increased from cycle to cycle. During waiting periods, the recrystallization of gelled lead dioxide was
Table 3 Potential shift of reduction peaks due to the concentration change of sulfuric acid medium

\begin{tabular}{llllll}
\hline $\begin{array}{l}\text { Molarity 1 } \\
\left(\mathrm{mol} \mathrm{dm}^{-3}\right)\end{array}$ & $\begin{array}{l}\text { Molarity 2 } \\
\left(\mathrm{mol} \mathrm{dm}^{-3}\right)\end{array}$ & $\begin{array}{l}\text { Measured } \\
\Delta E_{\text {peak,R } 1 / \mathrm{V}}\end{array}$ & $\begin{array}{l}\text { Calculated } \\
\Delta E_{\text {peak,R } 1 / \mathrm{V}}\end{array}$ & $\begin{array}{l}\text { Measured } \\
\Delta E_{\text {peak,R2 }} / \mathrm{V}\end{array}$ & $\begin{array}{l}\text { Calculated } \\
\Delta E_{\text {peak,R2 }} / \mathrm{V}\end{array}$ \\
\hline 0.5 & 2.5 & 0.12 & 0.12 & 0.01 & 0.06 \\
2.5 & 3.5 & 0.04 & 0.05 & 0.01 & 0.02 \\
3.5 & 5.0 & 0.00 & 0.07 & 0.01 & 0.03 \\
\hline
\end{tabular}




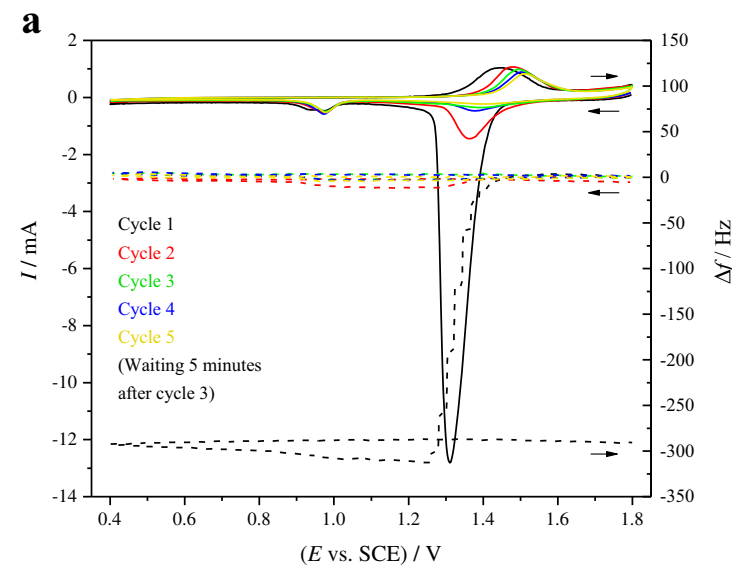

Fig. 4 a Cyclic voltammograms (solid line) and simultaneous frequency measurements (dashed line) during the discharge of electrodeposited $\mathrm{PbO}_{2}$ layer in $5.0 \mathrm{M} \mathrm{H}_{2} \mathrm{SO}_{4}$ solution. The scan rate was $50 \mathrm{mV} \mathrm{s}{ }^{-1}$ in the potential range of +1.8 to $+0.4 \mathrm{~V}$ vs. SCE. A 5-min-long waiting time

experienced in this case, too; however, it was not as significant as it is shown in Fig. $4 \mathrm{a}$ and $\mathrm{b}$. The effective molar mass

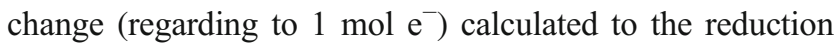
peak of $\mathrm{Au}_{2} \mathrm{O}_{3}$ was $9 \pm 1 \mathrm{~g}$ in all cases, which was in an excellent agreement with Reaction 4. In addition, it was also observed that between +0.8 and $+0.4 \mathrm{~V}$ vs. SCE, the film underwent a morphological change, which was practically the same during the whole process.

The relaxation of the lead dioxide layer after different waiting times (after cyclization until constant cyclic voltammograms were obtained) was also studied in $1.5 \mathrm{M} \mathrm{H}_{2} \mathrm{SO}_{4}$ solution (Fig. 7).

The open-circuit potential of the lead dioxide/lead sulfate system (Reaction 3a) in this medium can be determined based on the Nernst equation; the calculated value is $+1.41 \mathrm{~V}$ vs. SCE [24]. However, it must be also mentioned in this case that due to the

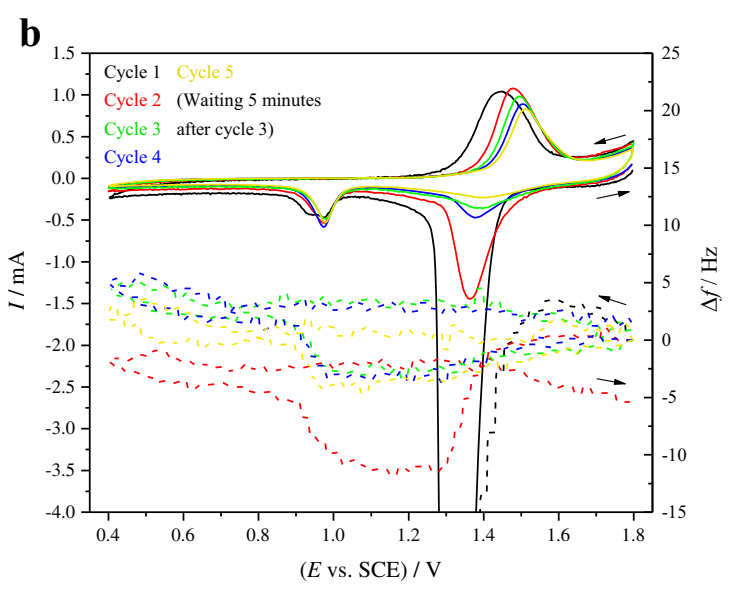

at open-circuit potential has been applied after the third cycle. $\mathbf{b}$ A portion of the curves shown in $\mathbf{a}$ in the current region between -4.0 and $+1.5 \mathrm{~mA}$ and in the frequency region between -15 and $+25 \mathrm{~Hz}$

presence of gelled material beside of the crystalline one, the open-circuit potential should be higher than the calculated value [23]. As seen in Fig. 7, neither the potential nor the frequency reached a certain value; their changing trends were monotonous. It is seen in Fig. $8 \mathrm{a}$ and $\mathrm{b}$ that in this less concentrated sulfuric acid solution, the oxidation of lead sulfate was more preferred. In such a way, more $\mathrm{PbO}_{2}$ could be prepared during cyclization; therefore, the concentration of $\mathrm{H}_{2} \mathrm{SO}_{4}$ was higher in the pores than in the bulk solution before waiting. In this case, the opposite processes could be expected than those occur in $5 \mathrm{M}$ sulfuric acid medium. The decrease of the potential and the increase of the frequency observed attest this explanation. If only diffusion kinetics prevailed, the curves would reach a certain value instead of changing practically monotonously from $900 \mathrm{~s}$. It is assumed that the diffusion had a contribution to the process mainly until that time; then, another phenomenon became significant. In order to
Fig. 5 Measuring the potential (solid line) and frequency change (dashed line) as a function of different waiting times after cyclization at open-circuit potential in $5.0 \mathrm{M} \mathrm{H}_{2} \mathrm{SO}_{4}$

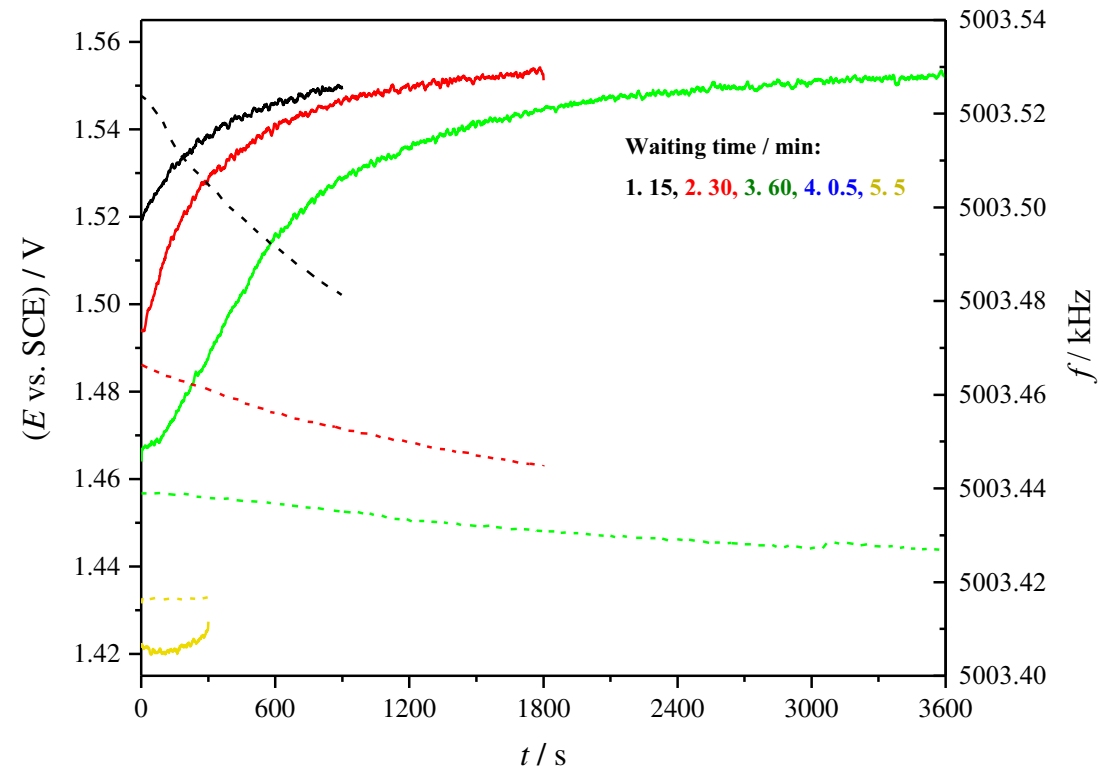




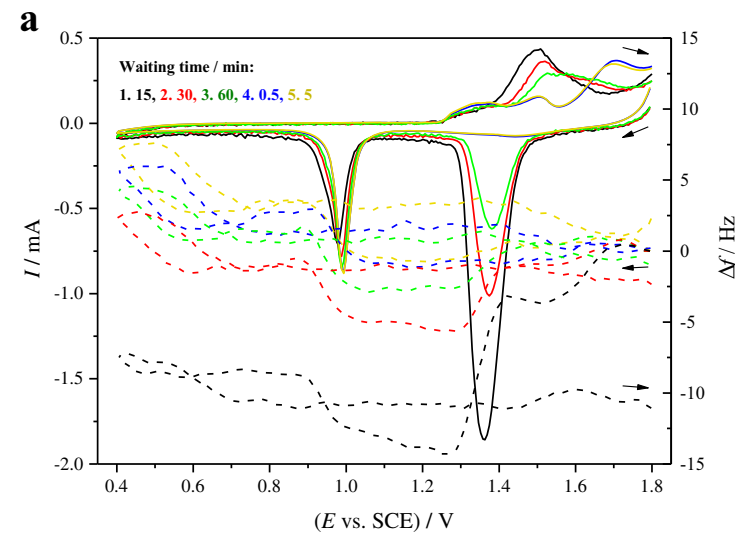

Fig. 6 a The 1st cyclic voltammograms (solid line) and simultaneous frequency measurements (dashed line) of $\mathrm{PbO}_{2}$ layers on a gold-coated quartz crystal measured after different waiting times. The electrolyte was

understand the reason of this observation, the first and the constant cyclic voltammograms with simultaneous frequency measurements by using $1.5 \mathrm{M}$ sulfuric acid solution were investigated (Fig. 8a, b).

Only a small amount of lead dioxide could be reduced during the first cycle after 1-h-long waiting period, but more and more amount was produced during the subsequent cycles. The main reason of this phenomenon is the chemical dissolution of lead dioxide according to Reaction 5 while the sulfation of the surface layer also occurred which is the well-known self-discharge mechanism of PAM of lead-acid batteries. It means that the diffusion of sulfuric acid was enhanced by this reaction as sulfate species were consumed.

$$
\begin{aligned}
& 2 \mathrm{PbO}(\mathrm{OH})_{2} \cdot(x-1) \mathrm{H}_{2} \mathrm{O}+2 \mathrm{H}^{+}+2 \mathrm{HSO}_{4}^{-} \rightleftharpoons 2 \mathrm{PbSO}_{4} \\
& +(\mathrm{x}+3) \mathrm{H}_{2} \mathrm{O}+\mathrm{O}_{2}
\end{aligned}
$$

b

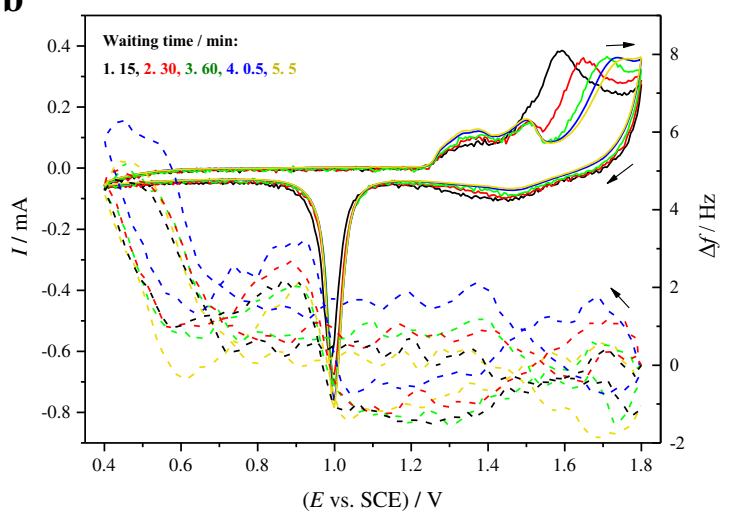

$5.0 \mathrm{M} \mathrm{H}_{2} \mathrm{SO}_{4}$ and the scan rate was $50 \mathrm{mV} \mathrm{s}^{-1}$. b The 10th cyclic voltammograms (solid line) and simultaneous frequency measurements (dashed line)

Thus, the electrochemically available lead dioxide was covered with less dense sulfate layer, making it temporarily inactive, isolated from the electrolyte. However, during the oxidation of lead sulfate at positive potentials, it was transformed to $\mathrm{PbO}_{2}$ with a smaller molar volume providing a free path for the diffusion of sulfuric acid to reach the deeper region of the layer. Based on the potential of the reduction peak of gold(III) oxide, the $\mathrm{H}_{2} \mathrm{SO}_{4}$ concentration inside the layer was practically the same (assumed to be same as the bulk concentration) during all CVs.

Three peaks were observed in the cyclic voltammogram between +1.5 and $+1.1 \mathrm{~V}$ vs. SCE during the cathodic potential scan. Based on the effective molar mass changes, the peak appeared at the least positive potential, the middle one, and the peak at the most positive potential belonged to the reduction of a rather crystalline lead dioxide, a rather gelled material, and a mixed one, respectively. From cycle to cycle, the peak currents of the two peaks appeared at less positive
Fig. 7 Measuring the potential (solid line) and frequency change (dashed line) in a function of different waiting times after cyclization at open-circuit potential in $1.5 \mathrm{M} \mathrm{H}_{2} \mathrm{SO}_{4}$

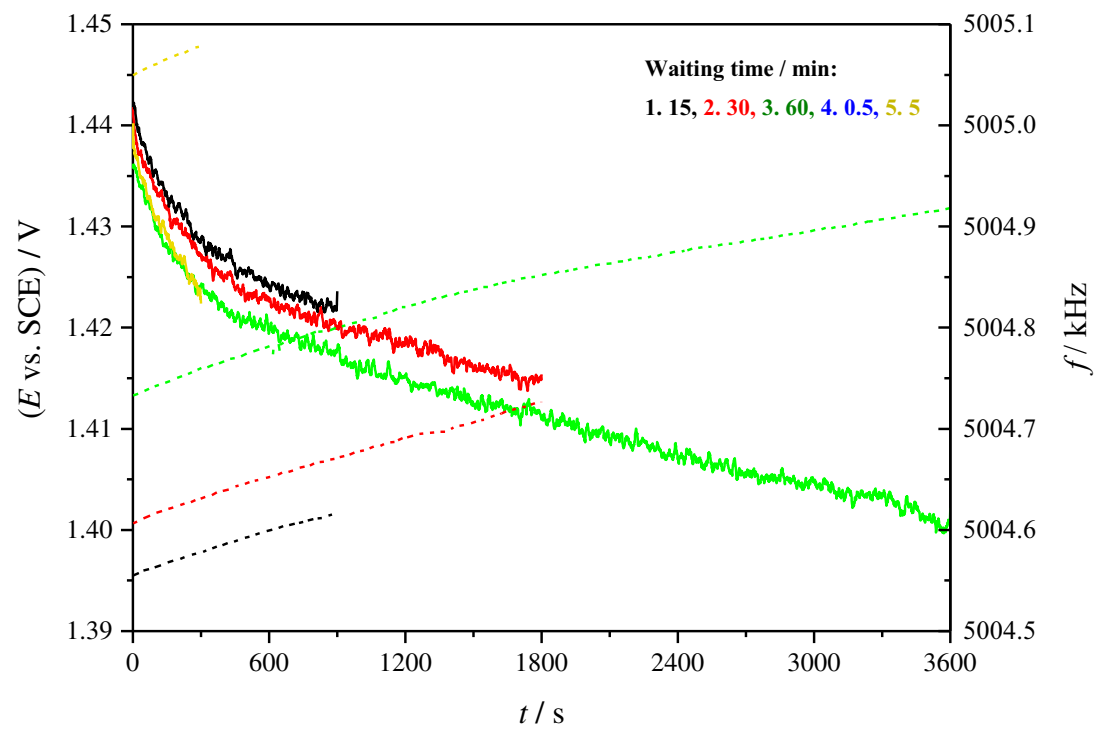




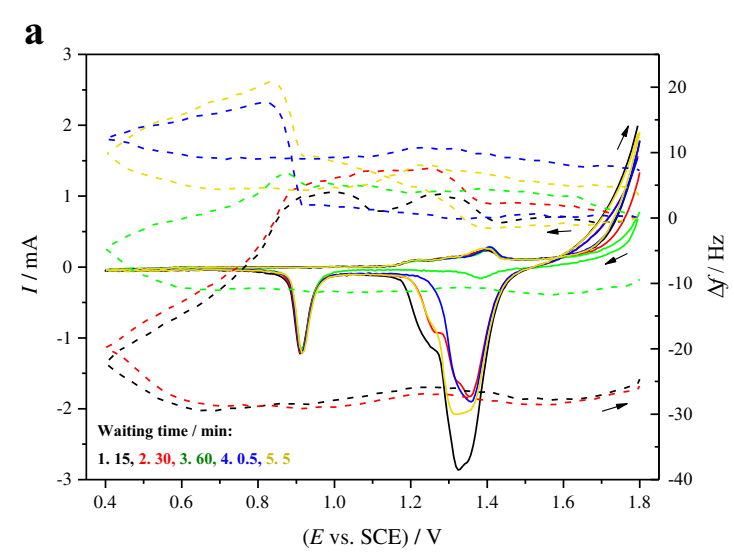

Fig. 8 a The 1 st cyclic voltammograms (solid line) and simultaneous frequency measurements (dashed line) of $\mathrm{PbO}_{2}$ layers on a gold-coated quartz crystal measured after different waiting times. The electrolyte was

potentials gradually decreased until they disappeared and only the peak at the highest positive potential was observable. During the waiting period, although the usual recrystallization process was experienced, it was continued by the sulfation of $\mathrm{PbO}_{2}$, resulting in the disappearance of this peak after waiting for $60 \mathrm{~min}$. Compared with the case when $5.0 \mathrm{M} \mathrm{H}_{2} \mathrm{SO}_{4}$ was used as electrolyte, the layer contained gelled parts in a higher extent at any stage of the investigation process. The reason of this phenomenon is that the dehydration effect of sulfuric acid is lower if its concentration is also lower. It means that if the medium contained $\mathrm{H}_{2} \mathrm{SO}_{4}$ in a higher concentration, the gelation was inhibited by the decrease in water activity according to Le Chatelier's principle based on Reaction 1.

Under such conditions, it is instructive that the mass changes during the reduction of gold(III) oxide cannot be directly related to Reaction 4 alone; therefore, ionic charge motion should play also a role which is seen in Fig. 8 a and b. Although the characteristics of the frequency changes were significantly different depending on the current state of the layer during the first cycles, it was very similar to what detected in the case of the constant CVs. It is reasonable to assume that a correlation exists between the presence of more crystalline phase of lead dioxide (having the lowest reduction potential) and the mass change during the reduction of $\mathrm{Au}_{2} \mathrm{O}_{3}$. It follows that if a significant amount of crystalline $\mathrm{PbO}_{2}$ had been reduced during the cathodic scan, a very small frequency decrease could be observed between ca. +0.85 and $+0.9 \mathrm{~V}$ vs. SCE. On the other hand, if the reduction was limited to gelled $\mathrm{PbO}_{2}$ only, during a single cycle, the frequency increased in this potential region. This phenomenon can be explained by the fact that the molar volume of gelled material was significantly higher than that of the crystalline one which means that permeability of the layer to sulfate ions (as counterions) became lower. According to Reaction 4, during the reduction of gold(III) oxide, the $\mathrm{H}^{+}$ions are consumed. The insertion of $\mathrm{H}^{+}$ ions into the layer causes a small mass change while the

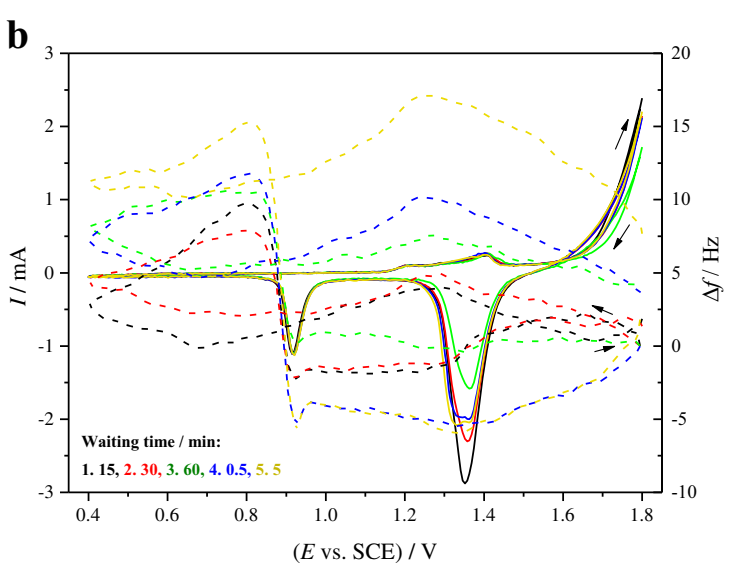

$1.5 \mathrm{M} \mathrm{H}_{2} \mathrm{SO}_{4}$ and the scan rate was $50 \mathrm{mV} \mathrm{s}^{-1}$. b The 10th cyclic voltammograms and (solid line) and simultaneous frequency measurements (dashed line)

opposite motion of the sulfate ions - which occurs to maintain the electroneutrality-involves a more substantial mass change. Therefore, the frequency changes observed are related to the resultant of these two processes. By decreasing the crystalline $\mathrm{PbO}_{2}$ content, the permeability of the layer also decreases which plausibly has a higher effect on the motion of the sulfate ions. Furthermore, because a relatively high mass increase can be observed between +0.8 and $+0.4 \mathrm{~V}$ vs. SCE where practically no current flows, it can be concluded that solvent sorption and consequently a morphological change take place.

\section{The application of a delay time at $1.8 \mathrm{~V}$ to achieve reliable voltammograms}

In less concentrated sulfuric acid media, cyclization can be carried out until constant cyclic voltammograms are obtained where peaks belonging to the reduction of lead dioxide and to the oxidation of lead sulfate appear. As it has already been discussed above, the reduction peak cannot be observed when more concentrated solutions are used. Therefore, this method is not suitable to study the oxidation/reduction behaviour, aging characteristics, etc. of lead dioxide layers in more concentrated sulfuric acid electrolyte. The reason of this phenomenon is that in these media, the oxidation of $\mathrm{PbSO}_{4}$ is a less favourable reaction because of high-sulfate ion activity. Less and less $\mathrm{PbO}_{2}$ could be reduced from cycle to cycle, so there is a need to carry out an additional oxidation step before each cycle and possibly also to wait some time for the replacement of consumed $\mathrm{H}_{2} \mathrm{SO}_{4}$ which occurs by diffusion. It is similar to the charging method of real batteries as the charging efficiency is not $100 \%$ near $100 \%$ SOC because of side reactions. That is why, a potentiostatic pre-oxidation step at $+1.8 \mathrm{~V}$ vs. SCE was applied before starting a new cyclic voltammogram to be able to characterize the aging properties of layers in such concentrated media. The duration of the step was optimized, 
and it was experienced that $15 \mathrm{~s}$ is enough to achieve the previously mentioned goals. Successive voltammograms shown in Fig. 9 were obtained by using $3.0 \mathrm{M} \mathrm{H}_{2} \mathrm{SO}_{4}$ which is in the middle working concentration region of sulfuric acid electrolyte in lead-acid batteries.

Except the reduction peak of lead dioxide, the peak currents became practically constant and reproducible after 2 cycles (pre-oxidation step was applied before each of them). The peak that appeared at $+1.4 \mathrm{~V}$ vs. SCE and also the respective frequency curve became constant only after 5 cycles.

During the cathodic scan, the peak belonging to the reduction of $\mathrm{PbO}_{2}$ in this medium split into two peaks. Based on the calculated effective molar mass values, the peaks observed at less positive potential (appearing as a shoulder) and at higher positive potential related to the reduction of a rather crystalline and a rather gelled material, respectively. In addition, it was also experienced that during the cyclization - as the layer aged - the film contained more and more gelled parts, although the degree of hydration began to stabilize after several cycles as the mass changes became practically the same.

During the first cycles, the $\mathrm{Au}_{2} \mathrm{O}_{3}$ reduction peak current increased as the gold substrate was oxidized in the preoxidation step, too. The peak was also slightly shifted into the direction of more positive potentials. It indicates that the sulfuric acid medium became more concentrated in the pores than in the bulk solution as the production and consumption of $\mathrm{H}_{2} \mathrm{SO}_{4}$ during charge-discharge cycles were balanced. During the calculation of the effective molar mass change, the monotonous decrease in frequency - began at approximately + $1.2 \mathrm{~V}$ vs. SCE during the negative potential sweep - must have been taken into account. If these corrections were used, the values calculated for the reduction of gold(III) oxide were about 9 to $10 \mathrm{~g} / \mathrm{mol}$ (regarding to $1 \mathrm{~mol} \mathrm{e}^{-}$) which corresponds well to Reaction 4.

\section{Conclusions}

In this study, the electrochemical behaviour, chargingdischarging characteristics, and aging properties of thick lead dioxide layers in sulfuric acid solutions of various concentrations have been investigated. Our goal was to characterize the electrodeposited $\mathrm{PbO}_{2}$ layer on gold substrate by using the cyclic voltammetry and in situ EQCM technique.

It was found that the electrochemical behaviours of the electrodeposited layers were significantly influenced by the concentration of the sulfuric acid electrolyte applied. In more concentrated solutions of $\mathrm{H}_{2} \mathrm{SO}_{4}$, the main reduction reaction was the transformation of lead dioxide to lead sulfate. In less concentrated sulfuric acid media $(c<$ ca. $2.5 \mathrm{M})$, albeit the reduction starts similarly, as the reaction progresses, the transformation of lead dioxide to lead(II) ion became the main reaction. These $\mathrm{Pb}^{2+}$ ions transformed into lead sulfate later by chemical reaction.

The reduction of $\mathrm{PbO}_{2}$ is more favourable in more concentrated sulfuric acid solutions. On the other hand, its formation via the oxidation of $\mathrm{PbSO}_{4}$ is a hindered process. From cycle to cycle, only a little portion of the formed lead sulfate could be reoxidized. However, the amount of lead dioxide reduced in the first cycle was only a small part of the whole electrodeposited amount. It means that a practically non-conductive and less dense lead sulfate layer covered the inner lead dioxide, making it temporarily electrochemically inactive and the concentration of $\mathrm{H}_{2} \mathrm{SO}_{4}$ also decreased in the pores. If certain
Fig. 9 Successive cyclic voltammograms obtained for an electrodeposited lead dioxide layer in $3 \mathrm{M} \mathrm{H}_{2} \mathrm{SO}_{4}$ with the scan rate of $50 \mathrm{mV} \mathrm{s}^{-1}$. Before the obtaining of each cyclic voltammogram, the potential was held at $+1.8 \mathrm{~V}$ vs. SCE for $15 \mathrm{~s}$

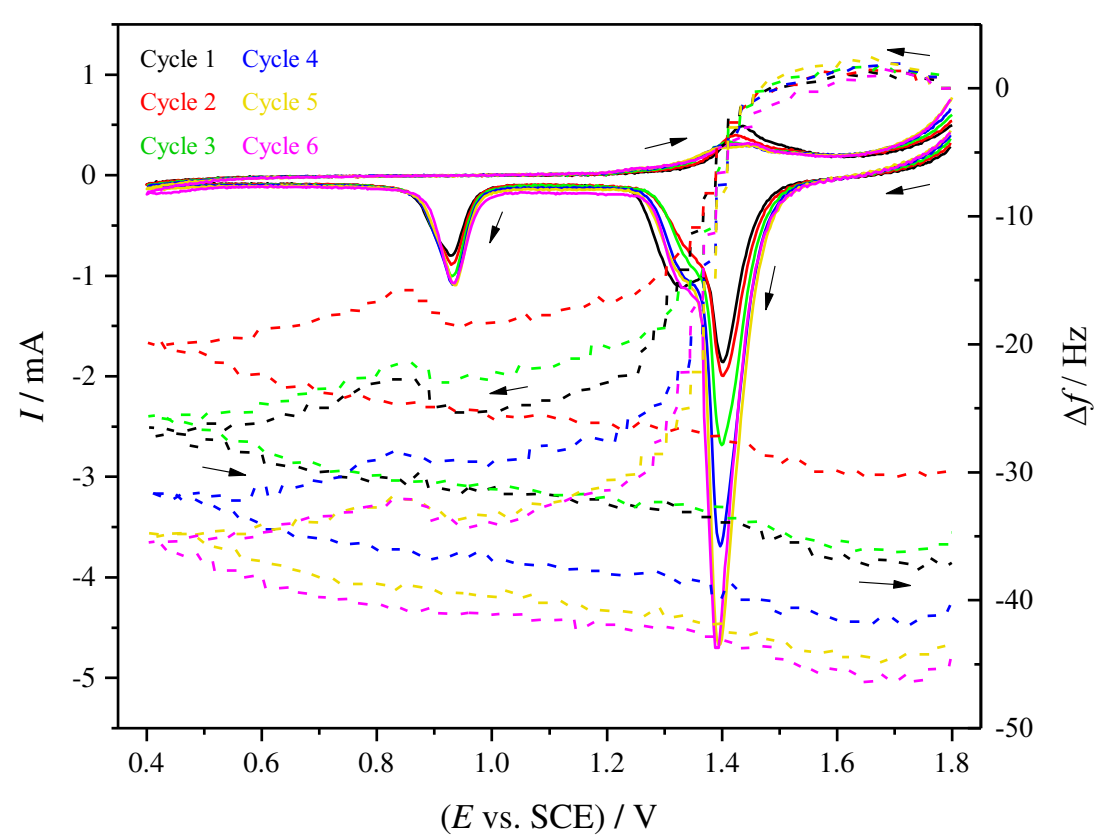


waiting time was applied, the amount of $\mathrm{PbO}_{2}$ which could be reduced in the next cycle increased significantly. This phenomenon is explained by both the dissolution of nonconductive $\mathrm{PbSO}_{4}$ layer and the acid replacement by diffusion.

In sulfuric acid media which concentration is less than ca. $2.5 \mathrm{M}$, significant quantity of lead sulfate could be reoxidized during the anodic scan. However, the reduction peak of lead dioxide was not observable in more concentrated solutions because the oxidation process was more hindered. Thus, with the usual cyclic voltammetric technique using multicycles, the oxidation/reduction behaviours and aging characteristics of $\mathrm{PbO}_{2}$ layers cannot be studied in a reliable manner. In order to overcome this problem, a potentiostatic pre-oxidation step at $+1.8 \mathrm{~V}$ vs. SCE for $15 \mathrm{~s}$ before starting a new voltammetric cycle was introduced. In this way, the aging properties of lead dioxide layers in such concentrated media can be studied appropriately.

It is also suggested that the gold substrate can be used as an internal reference electrode to follow the $\mathrm{pH}$ changes within the surface layer by monitoring the peak potential of the reduction peak of $\mathrm{Au}_{2} \mathrm{O}_{3}$ which is practically independent from the chemical forms of covering lead compounds.

Acknowledgements Open access funding provided by Eötvös Loránd University (ELTE).

Open Access This article is distributed under the terms of the Creative Commons Attribution 4.0 International License (http:// creativecommons.org/licenses/by/4.0/), which permits unrestricted use, distribution, and reproduction in any medium, provided you give appropriate credit to the original author(s) and the source, provide a link to the Creative Commons license, and indicate if changes were made.

\section{References}

1. Pavlov D (2011) Lead-acid batteries: science and technology. Elsevier, Oxford

2. Garche J, Karden E, Moseley PT, Rand DAJ (2017) Lead-acid batteries for future automobiles. Elsevier, Oxford

3. Karami H, Shamsipur M, Ghasemi S, Mousavi MF (2007) Leadacid bipolar battery assembled with primary chemically formed positive pasted electrode. J Power Sources 164:896-904

4. Petersson I, Berghult B, Ahlberg E (1998) Thin lead dioxide electrodes for high current density applications in semi-bipolar batteries. J Power Sources 74:68-76

5. Johnson DC, Feng J, Houk LL (2000) Direct electrochemical degradation of organic wastes in aqueous media. Electrochim Acta 46: 323-330

6. Chen S, Jiang F, Xie X, Zhou Y, Hu X (2016) Synthesis and application of lead dioxide nanowires for a PEM ozone generator. Electrochim Acta 192:357-362
7. Amadelli R, Armelao L, Velichenko AB, Nikolenko NV, Girenko DV, Kovalyov SV, Danilov FI (1999) Oxygen and ozone evolution at fluoride modified lead dioxide electrodes. Electrochim Acta 45: 713-720s

8. Pereira JF, Figueiredo RS, Ponce-de-León C, Bertazzoli R (2016) Platinum-free lead dioxide electrode for electrooxidation of organic compounds. J Solid State Electrochem 20:1167-1173

9. Czerwiński A, Żelazowska M, Grdeń M, Kuc K, Milewski JD, Nowacki A, Wójcik G, Kopczyk M (2000) Electrochemical behavior of lead in sulfuric acid solutions. J Power Sources 85:49-55

10. Derafa I, Zerroual L, Matrakova M (2018) On the electrochemical activity of $\beta$-lead dioxide in sulfuric acid solution: a comparative study between the chemical and electrochemical routes. J Solid State Electrochem 22:1175-1183

11. Ruetschi P (2004) Aging mechanisms and service life of lead-acid batteries. J Power Sources 127:33-44

12. Oliveira CP, Lopes MC (2004) Early stages of the lead-acid battery discharge. J Power Sources 138:294-300

13. Pech D, Brousse T, Bélanger D, Guay D (2009) EQCM study of electrodeposited $\mathrm{PbO}_{2}$ : investigation of the gel formation and discharge mechanisms. Electrochim Acta 54:7382-7388

14. Wei J, Gu Y, Guo Z, Deng C, Xie M, Li J, Xiong R, Xue Y, Wang L, Zhao $\mathrm{H}, \mathrm{Wu} \mathrm{X}$ (2019) EQCM study of hydrated $\mathrm{PbO}_{2}$ content and its influence on cycling performance of lead-acid batteries. J Energy Storage 21:706-712

15. Sauerbrey G (1959) Verwendung von Schwingquarzen zur Wägung dünner Schichten und zur Mikrowägung. Z Phys 155: 206-222

16. Taguchi M, Sugita H (2002) Analysis for electrolytic oxidation and reduction of $\mathrm{PbSO}_{4} / \mathrm{Pb}$ electrode by electrochemical QCM technique. J Power Sources 109:294-300

17. Kanazawa KK, Gordon JG (1985) The oscillation frequency of a quartz resonator in contact with a liquid. Anal Chim Acta 175:99 105

18. Broda B, Inzelt G (2018) Microgravimetric study of electrodeposition and dissolution of lead dioxide on gold and platinum substrates. J Solid State Electrochem 22:1-11

19. Robinson RA, Stokes RH (2002) Electrolyte solutions. Courier Corporation, North Chelmsford

20. Das K (1988) Single ion activities in aqueous sulfuric acid solutions: a new extra-thermodynamic assumption. J Solut Chem 17: 327-336

21. Carr JP, Hampson NA (1972) The lead dioxide electrode. Chem Rev 72:679-703

22. Pourbaix M (1974) Atlas of electrochemical equilibria in aqueous solutions. National Association of Corrosion Engineers, Houston

23. Pilatowicz G, Budde-Meiwes H, Kowal J, Sarfert C, Schoch E (2014) Comprehensive study of relaxation behaviour of lead-acid batteries for state-of-charge estimation in automotive applications. Proc. of the 9th international conference on lead-acid batteries, Bulgaria 1:1-4

24. Bullock KR (1991) The electromotive force of the lead-acid cell and its half-cell potentials. J Power Sources 35:197-223

Publisher's note Springer Nature remains neutral with regard to jurisdictional claims in published maps and institutional affiliations. 